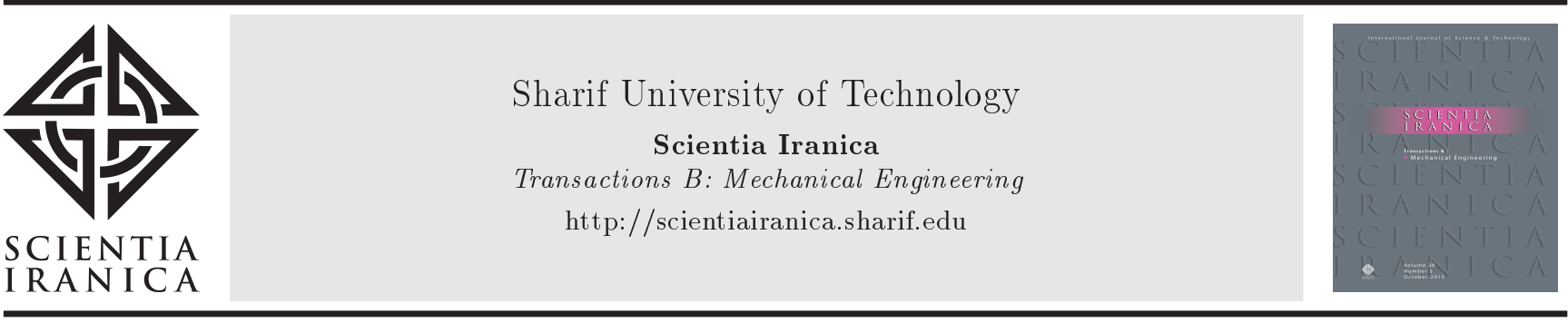

\title{
Taguchi optimization of fused deposition modeling process parameters on mechanical characteristics of PLA + filament material
}

\author{
M. Kamª ${ }^{a}$ A. İpekçi ${ }^{a, *}$, and Ö. Şengüil ${ }^{b}$ \\ a. Department of Mechanical and Metal Technologies, Cumayeri Vocational School, Düzce University, 81700 Duzce, Turkey. \\ b. Department of Mechanical Engineering, Düzce University, 81620, Düzce, Turkey.
}

Received 19 October 2020; received in revised form 21 January 2021; accepted 24 May 2021

\author{
KEYWORDS \\ FDM; \\ PLA; \\ Tensile strength; \\ Taguchi; \\ Optimization.
}

\begin{abstract}
This study attempts to investigate the effect of Fused Deposition Modeling (FDM) process parameters on mechanical characteristics with Taguchi optimization method. Three different FDM process parameters including filling structures (rectilinear, triangular, and full honeycomb), occupancy rates $(10,30$, and $50 \%$ ), and table orientation $\left(0,60\right.$, and $\left.-45^{\circ}\right)$ were specified as variable parameters for experiments. Other parameters kept fixed for each tensile and izod impact test samples were printed in line with the ISO 527-Type IV and ISO 180-Type I standards. The results found tensile strength and izod impact values to be directly proportional to the occupancy rate. The difference between the estimation model and the results of experiments did not exceed the maximum value of $1.8 \%$. Thus, by using the equations derived from this optimization, printing parameters can be determined for the desired tensile strength and izod impact values. By improving the material properties using modified PLA+ filament material as observed in the results, it is possible to provide support for researchers, design engineers, and manufacturer to optimize raw-material usage and margin.
\end{abstract}

(C) 2022 Sharif University of Technology. All rights reserved.

\section{Introduction}

In every sector of manufacturing, technological innovations play a significant role in keeping companies competitive by shortening the release time of products to the market [1]. Recently, use of Rapid Prototyping (RP) technologies in industrial applications is increasing. Three-Dimensional (3D) printers, known as one of Additive Manufacturing (AM) methods, are used in both academic and industrial areas [2]. This technology allows producing a preliminary prototype of the design easily and quickly [3]. Production with 3D printing

*. Corresponding author. Tel.: +905071423852 E-mail address: ahmetipekci@duzce.edu.tr (A. Ipekçi)

doi: 10.24200 /sci. 2021.57012 .5020 has become a focus of interest in many fields such as automotive, civil aviation, medical devices, and dental applications. In addition, the use of tissues and implants in the fields of medicine and denistry is becoming widespread with $3 \mathrm{D}$ printing [4]. 3D printing is the process of producing deposition materials layer by layer to produce parts from computer-aided designed models instead of subtractive manufacturing methods [5]. 3D printing is characterized by major advantages including the reduction of both process time and raw material. There are many methods in this technology and the differences between them are generally related to how the materials are formed. Stereolithograhpy (SLA), Selective Laser Sintering (SLS), and Digital Light Processing (DLP) are among the most applied methods for $3 \mathrm{D}$ printing [6]. 3D printing uses heat-formable thermoplastic materials in this method (PLA, ABS, 
etc.) [7]. FDM technology is a complex process that is affected by many parameters. Generally, filament material, build orientation, extrusion temperature, layer thickness, raster width, and raster angle are preferred as effective parameters in mechanical properties.

Another study employed FDM method in conjunction with ABS material to examine layer thickness, build orientation, filling structure, and occupancy rate parameters and optimize the effect of process parameters on compressive strength. According to the results of this study, it was stated that the $3 \mathrm{D}$ printed product with an occupancy rate of $80 \%$, gryoid filling structure, and $90^{\circ}$ built orientation parameters yielded very close results to the fully filled product [8].

Another study investigated the effects of filling structures on 3D printed parts. Five filling structures (honeycomb, solid, grid, wiggle, and linear) were combined to investigate their effect on tensile strength analysis. PLA material samples were produced in two different directions: straight and edge. They stated that grid and honeycomb filling structures had the highest strength; their weight was lighter than solid; and the power was reduced by increasing the construction orientation in the study [9].

A research study targeted PLA material based on the experimental design. In addition, other process parameters including layer thickness, material deposition speed, occupancy rate, and filling structures were taken into account. It was found that layer thickness parameter significantly affected the tensile properties [10].

In similar studies, the relationships between mechanical properties and surface roughness values and system vibrations were investigated. The occupancy rate of $50 \%$ was fixed in the form of rectilinear filling from Polyethylene Terephthalate Glycol (PET-G) material for different raster angles and printing speeds. As a result, it was demonstrated that the printing speed of $3600 \mathrm{~mm} / \mathrm{s}$ with raster angles of $60^{\circ}$ and $30^{\circ}$ was optimum in terms of mechanical properties and vibration $[11,12]$.

In similar studies on mechanical properties, PET$G$ filament material was used. In addition, in different filling types (grid, rectilinear, wiggle, triangular, and honeycomb), the results mainly reported the effects of printing patterns on the product strength. The strength values obtained for the products manufactured as rectilinear filling were approximately $15 \%$ higher than those for other filling structures. In addition, it is reported that honeycomb filling style has greater elongation than other filling structures [13-15].

Scientists adopt the process of optimization to reduce the number of changes in a product by controlling the parameters and features related to product design and development. The selected input parameters affect the final performance of a product without a doubt. Many methods including Taguchi's Orthogonal Array and Response Surface Methodology (RSM) are generally adopted by scientists to establish the experimental setup and the experimental data are further analyzed to obtain the optimum and significant parameters that have maximum effect over final results for study $[16,17]$.

In another study, mechanical properties and product cost were examined; layer thickness (0.15, 0.20, and $0.25 \mathrm{~mm})$, raster angles $\left(15^{\circ}, 45^{\circ}\right.$, and $\left.75^{\circ}\right)$, and table orientations (flat, horizontal, and vertical) were selected as effective parameters. In addition, the results were subjected to Taguchi optimization. The results reported that the raster angle of $45^{\circ}$ had the highest mechanical properties. They reported that optimum $3 \mathrm{D}$ printing process parameters for product cost included horizontal table orientation, layer thickness of $0.25 \mathrm{~mm}$, and raster angle of $75^{\circ}[18]$.

The effects of ABS and Nylon materials on the tensile strength values and dimensional accuracy of parameters by $3 \mathrm{D}$ printing were examined in another study. The chosen effective parameters include part orientation on table, layer height, and shell numbers. To reduce the number of experiments, different combinations and levels of different parameters were determined using the Taguchi's $\mathrm{L}_{9}$ orthogonal array. They reported that the orientation angle of part and shell numbers had a significant effect on tensile strength and moderately affected dimensional accuracy [19].

In a separate research, the mechanical properties of composites consisting of flexible plastic and natural fibers were studied. The impact strength and tensile strength values of the samples obtained from fiber and rubber in layers were examined. For decisionmaking, multi-objective optimization methods were employed [20].

A detailed review study reports that the reduction of the layer thickness does not yield a practical result as it extends the production time excessively. Many studies have analyzed the effects of parameters including printing speed, filling structures, and occupancy rate on mechanical properties. Contrary to the other studies reviewed, maximizing the occupancy rate does not increase the strength much after $50 \%$ occupancy rate and, also, makes the printing time difficult to apply in practice. Another issue addressed in these studies is that the filling structure, which gives the best mechanical properties according to the type of material, varies. In fact, different filling structures are recommended for improving different mechanical properties according to type of filament material. On the other hand, fused deposition modeling is a complicated process that has many affective parameters for product quality and material properties. According to the reported results, in terms of mechanical properties, the use of optimization is an important requirement that has arisen and is strictly dependent on the material and how it is applied [21]. 
In the literature, filling structure, occupancy rate, and table orientation are the most effective 3D printing parameters for the strength of products with $3 \mathrm{D}$ printing method [16-25].

Generally, the examined studies address the tensile strength values of ABS material and there is no study that examines the effects of the most important $3 \mathrm{D}$ printing process parameters (filling structure, occupancy rate, and table orientation) for the new modified PLA + material. In addition, in general, izod impact values for PLA + material are not mentioned in the studies $[17,26]$. In the literature, research studies have focused on tensile strength, ultimate strength, and percentage elongation. This study aimed to present the damping ability of the parts experimentally and statistically, which worked in impact environments where impact resistance tests were performed in order to set an example for the industry employees.

In this context, test samples were produced from PLA + material with three different filling structures, different occupancy rates, and table orientations using the FDM method. Within the scope of the study, experimental and statistical analyses were carried out by applying the Taguchi methodology to maximize strength, percent elongation, and Izod impact values. Effects of FDM process parameters on mechanical characteristics were examined by Taguchi optimization of process parameters. Thanks to the derived equations of optimization results, an attempt was made to provide the people active in this field to predict the tensile strength and izod impact values upon changes in the effective parameters.

\section{Material and method}

In this study, mechanical characteristics of the 3D printed PLA filament material samples were investigated experimentally and statistically. PLA filament material used in the scope of the study is manufactured by ESUN and can be found under the trade name PLA + with $1.75 \mathrm{~mm}$ diameter. The mechanical properties of this filament material, which is suitable for use with $3 \mathrm{D}$ printing, are given in Table 1 . The main reason for using PLA within the scope of the research is that this plastic material has more advantages than ABS [27]. PLA is a biodegradable thermoplastic polyester material derived from cleaner sources that contains lower toxicity and requires lower temperatures with $3 \mathrm{D}$ printing, thus positively influencing the energy consumption. PLA + based tensile and Izod test samples were produced on a Cartesian 3D printer. The $3 \mathrm{D}$ printer has a $0.4 \mathrm{~mm}$ nozzle diameter that has opensource software as a commercial device. In this study, test samples were prepared for tensile tests according to ISO 527 and Izod impact tests according to ISO 180 standards. For this purpose, the solid model of test samples was created using SolidWorks design software and converted into STL file format for 3D printer slicing operation. The solid models of the samples were converted to Geometric Code (G-code) files using Simplfy3D slicing software and made ready for production.

\subsection{Experimental design and optimization}

The mechanical properties of the produced samples are related to the decision of process parameters by the FDM method. Occupancy rate is the most effective parameter for determining the strength of the product. Of course, the type of filament material used affects the strength. In $3 \mathrm{D}$ printing, the dimensions of the gaps from $30-40 \%$ to $100 \%$ change insignificantly. For this reason, the occupancy rate of $50 \%$ is sufficient to produce high-strength models with less material. Therefore, in our study, the occupancy rates were determined as 10\%, 30\%, and 50\%. Filling structure is the shape of the material inside a $3 \mathrm{D}$ printed part. By ranging from lines to geometric shapes, filling structures can affect mechanical properties, weight, and printing time directly. Similar to the occupancy rate, some filling structures are better than the others. Depending on the slicing software used, there are different types of filling structures; yet, the three most used ones (rectilinear, triangular, and full honeycomb) appear in all slicing programmes. The table orientation points to the direction in which the part is positioned on the printing table along the $\mathrm{X}$ and $\mathrm{Y}$ axes. The table orientation angle and the filling structure of the part determine the shape of the inner structure. 3D prints are created layer by layer; however, how the layers are created has a large impact on mechanical properties.

In this context, three different occupancy rates $(10,30$, and $50 \%)$ and filling structures (triangular, rectilinear, and full honeycomb) as well as three different table orientation angles $\left(0,60\right.$, and $\left.-45^{\circ}\right)$ were determined and the Taguchi L9 experimental design was applied to printing test samples. All 3D printing parameters used in this experimental study are given in Table 2 .

Table 1. Properties of PLA+ filament material [28].

\begin{tabular}{ccccccc}
\hline $\begin{array}{c}\text { Printing } \\
\text { temperature } \\
\left({ }^{\circ} \mathbf{C}\right)\end{array}$ & $\begin{array}{c}\text { Density } \\
\left(\mathrm{g} / \mathbf{c m}^{\mathbf{3}}\right)\end{array}$ & $\begin{array}{c}\text { Maximum service } \\
\text { temperature } \\
\left({ }^{\circ} \mathbf{C}\right)\end{array}$ & $\begin{array}{c}\text { Ultimate } \\
\text { strength } \\
(\mathbf{M P a})\end{array}$ & $\begin{array}{c}\text { Elongation } \\
\text { at break } \\
(\mathbf{\%})\end{array}$ & $\begin{array}{c}\text { Flexural } \\
\text { strength } \\
(\mathbf{M P a})\end{array}$ & $\begin{array}{c}\text { Izod impact } \\
\text { strength } \\
\left(\mathbf{k J} / \mathbf{m}^{\mathbf{2}}\right)\end{array}$ \\
\hline $190-220$ & 1.24 & 60 & 45.6 & 6 & 103 & 5.1 \\
\hline
\end{tabular}


Table 2. FDM process parameters and 3D printer features.

\begin{tabular}{ll}
\multicolumn{1}{c}{ Features } & \multicolumn{1}{c}{ Values } \\
\hline Nozzle diameter $(\mathrm{mm})$ & 0.40 \\
Extruder temperature $\left({ }^{\circ} \mathrm{C}\right)$ & 205 \\
Table temperature $\left({ }^{\circ} \mathrm{C}\right)$ & 60 \\
Extrusion width $(\mathrm{mm})$ & 0.35 \\
Layer height $(\mathrm{mm})$ & 0.2 \\
Printing speed $(\mathrm{mm} / \mathrm{min})$ & 3600 \\
Idle running $(\mathrm{mm} / \mathrm{min})$ & 4800 \\
Ambient temperature $\left({ }^{\circ} \mathrm{C}\right)$ & $24 \pm 1$ \\
Model & $\mathrm{Rigid} 3 \mathrm{D}$ Zero2 \\
Printing volume & $200 * 200 * 200 \mathrm{~mm}$ \\
Machine dimension & $390 * 460 * 460 \mathrm{~mm}$ \\
Tolerance & $0.05-0.1 \mathrm{~mm}$ \\
Power & $600 \mathrm{~W}$ \\
Extruder nozzle & 1 \\
Processor & Arduino processor \\
\hline
\end{tabular}

For each test, three samples were produced at the same time. Detailed images of $3 \mathrm{D}$ printing process and dimensions of the IS0 527-Type IV sample are given in Figure 1. Tensile strength value is an important physical specification of material in any application. FDM process parameters and levels of test samples are given in Table 3 .

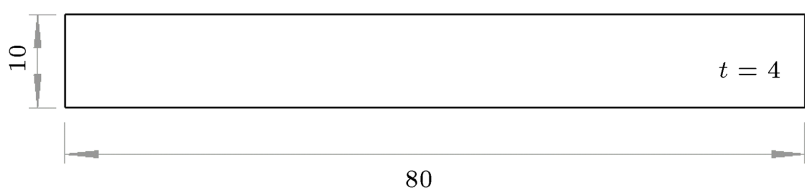

Figure 2. IS0 180-Type I test sample dimensions (mm).

Dimensions of the ISO 180-Type I sample are given in Figure 2. Cross-sectional images of different filling shapes (rectilinear, triangular, and full honeycomb) and table orientation of samples are given in Figure 3.

Tensile tests were conducted using a 10-tonne tensile testing device (UTEST brand) at Düzce University, Mechanical Engineering Laboratory. The tensile test process is given in Figure 4 . The tensile test speed of $5 \mathrm{~mm} / \mathrm{min}$ was chosen in line with ISO 527 test standard and all tests were carried out under equal conditions.

Izod tester is given in Figure 5. The tests were repeated three times in line with ISO 180 test standard.

Izod test device has Joule pendulum's energy of 2.75 , movement angle of 150 degrees, width of $4 \mathrm{~mm}$, and notch thickness of $2 \mathrm{~mm}$.

In order to minimize experimental errors, three tests were repeated for each condition and the obtained evaluations averaged the tensile strength values. In the last stage of this study, statistical analysis and optimization were carried out depending on tensile strength of the $3 \mathrm{D}$ printing parameters with PLA + material. In this context, ANOVA was applied at a
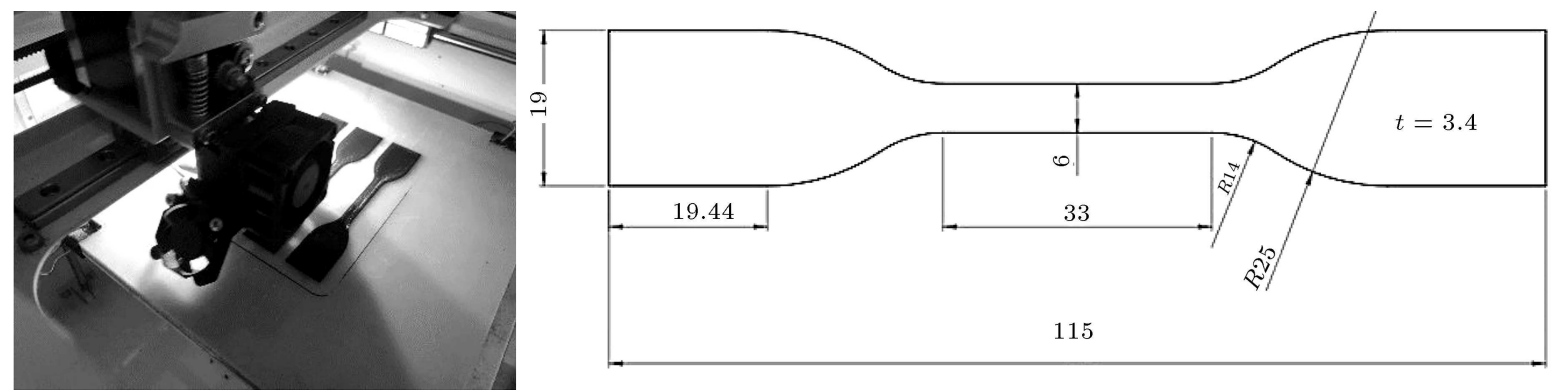

Figure 1. Printing process of samples and ISO 527-Type IV test sample dimensions (mm).

Table 3. Printing process parameters and levels (Taguchi $\mathrm{L}_{9}$ ).

\begin{tabular}{ccll}
\hline Factors & Unit & \multicolumn{1}{c}{ Levels } & \multicolumn{1}{c}{ Output } \\
\hline & & 1. Full Honeycomb & \\
Filling structures & - & 2. Rectilinear & Tensile strength values (MPa), \\
& & 3. Trianglular & Percentage elongation at break (\%), \\
& & & Izod impact values \\
Occupancy rates & $\%$ & $10,30,50$ & \\
Table orientation & $\circ$ & $0,60,-45$ & \\
\hline
\end{tabular}



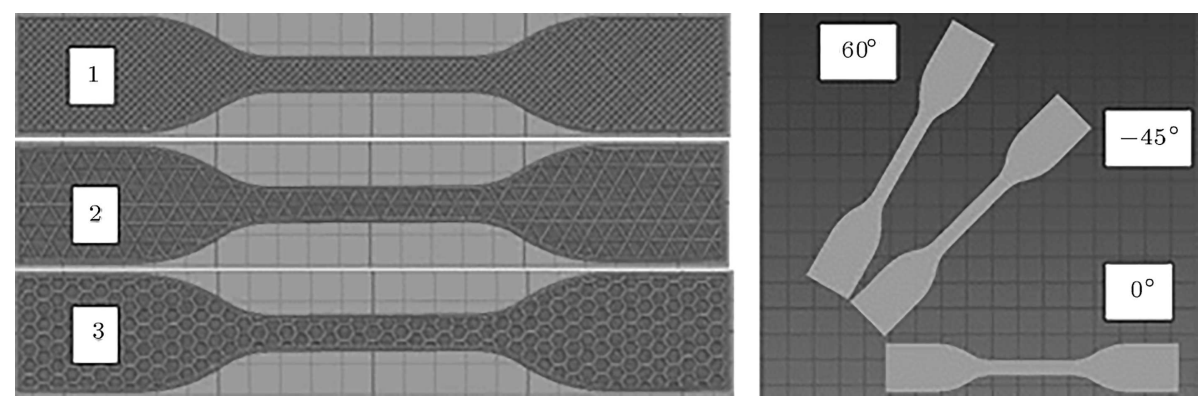

Figure 3. Filling structures. 1: Rectilinear, 2: Triangular, and 3: Full honeycomb. Table orientations: $60^{\circ},-45^{\circ}$, and $0^{\circ}$.

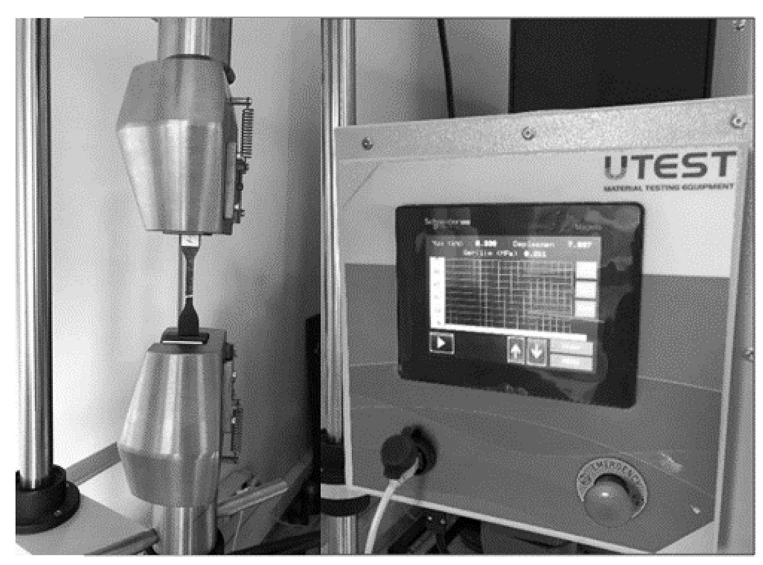

Figure 4. Tensile testing device and tensile test process.

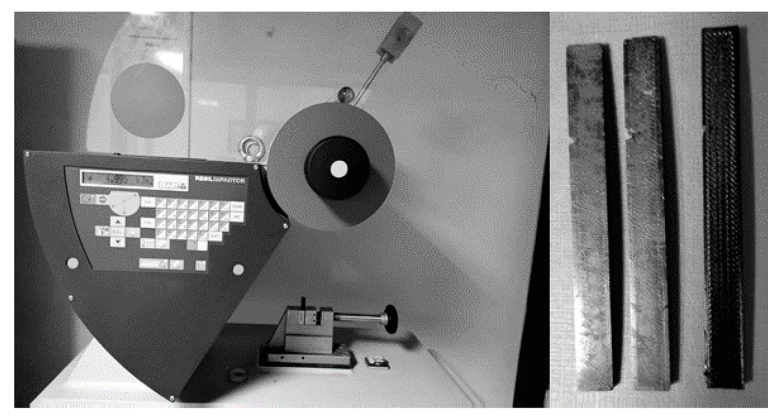

Figure 5. Izod impact test device and test sample.

confidence level of $95 \%(\alpha=0.05)$ to the experimental results, and the effect levels of the filling structure, occupancy rate, and table orientation with respect to the tensile strength were defined.

Maximum tensile strength value, elongation value, and izod impact values as performance characteristics are required for the FDM method. The "larger is better" function of Taguchi was used in optimization, as shown in Eq. (1). Taguchi determines the goal function of Signal/Noise $(S / N)$ ratio to illustrate the effect of the levels of printing parameters [29].

$$
S / N=-10 \log \left(\frac{1}{n} \sum_{i=1}^{n} \frac{1}{y_{i}^{2}}\right) .
$$

\section{Assessment of experimental and statistical results}

\subsection{Tensile and Izod test results of experiments}

Taguchi $\mathrm{L}_{9}$ experiment layout and signal to statistical results are given in Table 4 . Tensile strength and elongation data obtained from tensile tests are given in Table 5 .

Table 5 shows that the average tensile strength increases proportionally as the occupancy rate increases with each filling structure. The largest average tensile strength value was provided in Sample 6. Further, the highest average percentage elongation value was provided in Sample 6. The least average tensile strength value was provided in Sample 1 . The lowest average percentage elongation value was observed in Sample 5 . In addition, the average percentage elongation of full honeycomb filling structure remained unaffected by other parameters.

Table 6 shows that the average Izod impact values increase proportionally as the occupancy rate with triangular and full honeycomb filling structures increases. The highest average Izod impact value was acquired in Sample 6. The lowest average Izod impact value was observed in Sample 7. Rectilinear filling structure and Izod impact values vary independently of parameters. In applications whose Izod impact values are significant, it is not appropriate to work at an occupancy rate of $30 \%$ or below.

\subsection{Statistical results}

Results of variance analysis are shown in Table 7 . Figure 6 shows the main signal-to-noise plot for the effects and levels of the $3 \mathrm{D}$ printing parameters. In order for the strength and impact values to be at the highest, the larger-is-better optimization function for the signal-to-noise ratio was determined using Minitab18 program. The optimized 3D printing parameters and their equivalent values are shown in Tables 8 and 9 . $R^{2}$ regression coefficient was calculated at $96.96 \%$ and standard deviation at 0.256661 . Linear regression equation is given in the following for estimation of tensile strength, percentage elongation at break, and 
Table 4. Taguchi $\mathrm{L}_{9}$ experiment layout and statistical results.

\begin{tabular}{cccccc}
\hline \multirow{2}{*}{ Samples } & $\begin{array}{c}\text { Filling } \\
\text { structures }\end{array}$ & $\begin{array}{c}\text { Occupancy rate } \\
(\boldsymbol{\%})\end{array}$ & $\begin{array}{c}\text { Table orientation } \\
\left({ }^{\circ}\right)\end{array}$ & $\begin{array}{c}\text { Signal to Noise } \\
(S / N)\end{array}$ & $\begin{array}{c}\text { Mean } \\
\text { value }\end{array}$ \\
\hline 1 & RC & 10 & 0 & -29.2087 & 8.9300 \\
2 & RC & 30 & 60 & -29.6540 & 10.2500 \\
3 & RC & 50 & -45 & -28.3809 & 11.9943 \\
4 & TA & 10 & 60 & -28.7850 & 10.7437 \\
5 & TA & 30 & -45 & -30.1238 & 11.4523 \\
6 & TA & 50 & 0 & -27.2702 & 14.0220 \\
7 & FH & 10 & -45 & -28.3814 & 9.7180 \\
8 & FH & 30 & 0 & -28.3806 & 10.0687 \\
9 & FH & 50 & 60 & -28.3805 & 11.3603 \\
\hline
\end{tabular}

Table 5. Tensile strength values and percentage elongation values of tensile tests.

\begin{tabular}{|c|c|c|c|c|c|c|c|c|}
\hline \multirow{2}{*}{ Samples } & \multicolumn{4}{|c|}{ Tensile strength (MPa) } & \multicolumn{4}{|c|}{ Elongation at break (\%) } \\
\hline & 1. Test & 2. Test & 3. Test & Average & 1. Test & 2. Test & 3. Test & Average \\
\hline 1 & 25.60 & 24.76 & 24.59 & 24.98 & 0.020 & 0.023 & 0.020 & 0.021 \\
\hline 2 & 28.58 & 28.66 & 28.08 & 28.44 & 0.020 & 0.021 & 0.018 & 0.019 \\
\hline 3 & 35.06 & 33.44 & 33.62 & 34.04 & 0.024 & 0.020 & 0.023 & 0.022 \\
\hline 4 & 29.11 & 31.22 & 30.95 & 30.42 & 0.021 & 0.022 & 0.021 & 0.021 \\
\hline 5 & 31.77 & 32.26 & 33.61 & 32.54 & 0.018 & 0.017 & 0.019 & 0.018 \\
\hline 6 & 37.62 & 38.89 & 38.92 & 38.47 & 0.023 & 0.030 & 0.022 & 0.025 \\
\hline 7 & 27.40 & 28.44 & 27.27 & 27.70 & 0.021 & 0.023 & 0.024 & 0.022 \\
\hline 8 & 29.36 & 25.02 & 28.10 & 27.49 & 0.021 & 0.024 & 0.021 & 0.022 \\
\hline 9 & 31.31 & 29.95 & 31.68 & 30.81 & 0.023 & 0.026 & 0.019 & 0.022 \\
\hline
\end{tabular}

Table 6. Izod impact test results.

\begin{tabular}{ccccc}
\hline \multirow{2}{*}{ Samples } & \multicolumn{4}{c}{ Izod impact values $\mathbf{( k J / \mathbf { m } ^ { \mathbf { 2 } } )}$} \\
\cline { 2 - 5 } & 1. Test & 2. Test & 3. Test & Average \\
\hline 1 & 1.692 & 1.987 & 1.692 & 1.790 \\
2 & 2.336 & 2.390 & 2.148 & 2.291 \\
3 & 1.520 & 1.799 & 2.444 & 1.921 \\
4 & 1.826 & 1.584 & 1.960 & 1.790 \\
5 & 1.638 & 2.014 & 1.745 & 1.799 \\
6 & 4.001 & 4.377 & 2.336 & 3.571 \\
7 & 1.504 & 1.369 & 1.423 & 1.432 \\
8 & 2.121 & 3.625 & 2.336 & 2.694 \\
9 & 4.001 & 3.840 & 1.907 & 3.249 \\
\hline
\end{tabular}

Izod impact values at a confidence interval of $95 \%$. Upon the application of the extracted equations instead of filling structure, the following numerical data are obtained: the numbers 1 for full honeycomb, 2 for rectilinear, and 3 for triangular, as shown in Table 3 . Linear regression equation used in the estimation of
Table 7. Variance analysis values.

\begin{tabular}{lccccc}
\hline \multicolumn{1}{c}{ Source } & DF & $\begin{array}{c}\text { Adj } \\
\text { SS }\end{array}$ & $\begin{array}{c}\text { Adj } \\
\text { MS }\end{array}$ & $\boldsymbol{F}$-value & $\boldsymbol{P}$-value \\
\hline Regression & 3 & 111.191 & 37.064 & 8.94 & 0.019 \\
Occupancy rate & 1 & 68.141 & 68.141 & 16.44 & 0.010 \\
Table orientation & 1 & 3.369 & 3.369 & 0.81 & 0.409 \\
Filling structures & 1 & 39.681 & 39.681 & 9.57 & 0.027 \\
Error & 5 & 20.722 & 4.144 & & \\
Toplam & 8 & 243.104 & & & \\
\hline
\end{tabular}

tensile strength values:

Tensile strength $(\mathrm{MPa})=20.42+0.1685$

$\times$ Occupancy rate $-0.0142 \times$ Table orientation

$+2.572 \times$ Filling structure. 


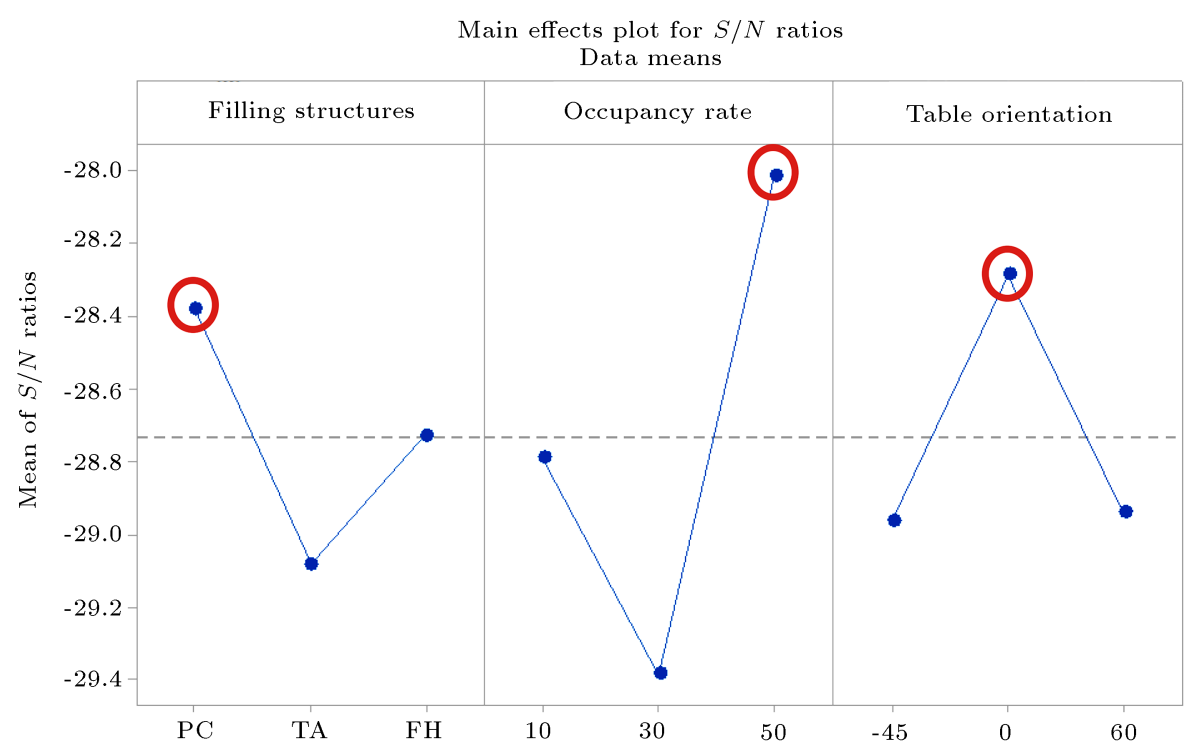

Signal-to-noise: larger is better

Figure 6. $S / N$ ratios of parameters for optimum $3 \mathrm{D}$ printing process parameters.

Table 8. Signal-to-noise ratios according to "larger is better" criterion.

\begin{tabular}{cccc}
\hline Level & Filling structures & Occupancy rate $(\%)$ & $\begin{array}{c}\text { Table } \\
\text { orientation }\left(^{\circ}\right)\end{array}$ \\
\hline 1 & -28.38 & -28.79 & -28.96 \\
2 & -29.08 & -29.39 & -28.29 \\
3 & -28.73 & -28.01 & -28.94 \\
Delta & 0.70 & 1.38 & 0.68 \\
Rank & 2 & 1 & 3 \\
\hline
\end{tabular}

Linear regression equation used in the estimation of tensile elongation at break:

$$
\begin{aligned}
& \text { Elongation at break }(\%)=0.02040+0.00005 \\
& \times \text { Occupancy rate }-0.000002 \\
& \times \text { Table orientation }-0.000333 \\
& \quad \times \text { Filling structure. }
\end{aligned}
$$

Linear regression equation used in the estimation of izod impact value:

Izod impact value $\left(\mathrm{kJ} / \mathrm{m}^{2}\right)=1.39+0.0311$

$$
\begin{aligned}
& \times \text { Occupancy rate }-0.00632 \\
& \times \text { Table orientation }-0.036 \times \text { Filling structure }
\end{aligned}
$$

As seen in Table 7 , when the $P$ values are examined, only the value of the table orientation parameter is above 0.05 . This situation shows that the effect of table orientation on mechanical properties is very lower than those of other parameters.
Table 8 shows the responses for signal-to-noise ratios. Such optimum 3D printing process parameters as rectilinear filling structure, $50 \%$ occupancy rate, and $0^{\circ}$ table orientation with $\mathrm{PLA}+$ filament were obtained. In a similar study, an optimization study was conducted in terms of compression strength. However, instead of the rectilinear filling structure that yields the best results, a gyroid filling method was preferred and ABS material was preferred as the material. The occupancy rate of $80 \%$ was suggested, which may not be effective in terms of printing speed and production costs. Our study selected the tensile and impact strength values as the most important mechanical characteristics obtained from 3D printed parts, constituting the condition for multi-criteria optimization. Our findings revealed the most suitable parameters in terms of printing cost for the most suitable modified filament for manufacturers [30].

Using Eqs. (2)-(4), the tensile strength, percentage elongation, and izod impact value were calculated for the proposed optimum process parameters, and the average test results of 3 test samples produced in these optimum parameters were compared. Thus, the results 
Table 9. Comparison of verification test results and calculated results for optimum parameters.

\begin{tabular}{lcc}
\hline \multicolumn{1}{c}{ Output } & Estimated values & Verifying test results \\
\hline Tensile strength $(\mathrm{MPa})$ & 33.99 & 33.15 \\
Elongation $(\%)$ & 0.024 & 0.023 \\
Izod impact value $\left(\mathrm{kJ} / \mathrm{m}^{2}\right)$ & 3.017 & 2.82 \\
\hline
\end{tabular}

Table 10. Comparison of the measured and estimated signal-to-noise and mean values using Taguchi method.

\begin{tabular}{ccccc}
\hline Sample no. & $\begin{array}{c}\text { Signal to noise } \\
(\boldsymbol{S} / \boldsymbol{N})\end{array}$ & $\begin{array}{c}\text { Mean } \\
\text { value }\end{array}$ & $\begin{array}{c}\text { Predicted signal to noise } \\
(\boldsymbol{S} / \boldsymbol{N})\end{array}$ & $\begin{array}{c}\text { Predicted mean } \\
\text { value }\end{array}$ \\
\hline 1 & -29.2087 & 8.9300 & -28.7005 & 9.2979 \\
2 & -29.6540 & 10.2500 & -29.9483 & 9.8688 \\
3 & -28.3809 & 11.9943 & -28.5949 & 12.0076 \\
4 & -28.7850 & 10.7437 & -28.9990 & 10.7569 \\
5 & -30.1238 & 11.4523 & -29.6156 & 11.8203 \\
6 & -27.2702 & 14.0220 & -27.5645 & 13.6408 \\
7 & -28.3814 & 9.7180 & -28.6756 & 9.368 \\
8 & -28.3806 & 10.0687 & -28.5946 & 10.0819 \\
9 & -28.3805 & 11.3603 & -27.8723 & 11.7283 \\
\hline
\end{tabular}

obtained in this study were verified, as shown in Table 9. Accordingly, high convergence values of $97.53 \%$ for tensile strength, $95.88 \%$ for percentage elongation, and $93.47 \%$ for izod impact value were obtained. In this context, it is noteworthy that the difference between the results of the verification experiment and those obtained from the Taguchi approach is negligible. Based on these results, it is possible that Taguchi optimization be successfully applied at a significance level of 0.05. In addition, in an optimization study of tensile strength and material weight for the unmodified PLA material, the MPa tensile strength of 37, which is the strength obtained at an occupancy rate of $80 \%$, can be obtained at an occupancy rate of $50 \%$ using the modified PLA + material and the parameters optimized in our study [31].

Table 10 shows that the difference between the estimation model and the experimental one did not exceed the maximum value of $1.8 \%$. In new studies, the optimization proposed for future works was taken into consideration and the mechanical characteristics of the newly modified PLA material and the optimum operating parameters to be used by the manufacturers were examined. In addition, another future study suggested in the review studies is that in addition to the selected parameters, practical equations were obtained for the strength values if different degrees were selected [32]. Similar results to those existing in the literature were obtained [33].

\section{Conclusion}

Results of the experiments were conducted for occupancy rate, filling structure, and table orientation, which were selected as 3D printing parameters, and their effects on mechanical characteristics were examined with the help of Taguchi optimization. The following main results are listed below:

- Statistical calculations required for the optimum selection of tensile strength values, percentage elongation and Izod impact values, rectilinear filling structure, $50 \%$ occupancy rate, and $0^{\circ}$ table orientation were determined. This study selected the tensile strength and impact strength, which are the most important mechanical characteristics of Taguchi optimization, and revealed the most suitable parameters in terms of printing cost for the most suitable modified PLA filament for manufacturers;

- In addition to the selected parameters, practical equations were obtained for the strength values if different degrees were selected. As a result of this study, the difference between the estimation equation and experimental results did not exceed the maximum value of $5 \%$.

- The average tensile strength increased proportionally as the occupancy rate increased with each filling structure. The average percentage elongation of 
full honeycomb filling structure was not affected by other parameters, and the most effective parameter for the mechanical characteristic was the rate of occupancy;

- The average Izod impact values increased proportionally as the occupancy rate increased with triangular and full honeycomb filling structures, unlike the rectilinear filling structure. Rectilinear filling structure and Izod impact values varied independently of the parameters. In applications whose Izod impact values are significant, it is not appropriate to work at an occupancy rate of $30 \%$ or below.

\section{Acknowledgements}

This study was presented at the 7th International Conference on Computational and Experimental Science and Engineering (ICCESEN 2020) and the summary was published.

\section{Nomenclature}

$3 \mathrm{D}$ Three-dimensional

ABS Acrylonitrile Butadiene Styrene

AM Additive Manufacturing

ANOVA Analysis Of Variance

CAD Computer Aided Design

DLP Digital Light Processing

FDM Fused Deposition Modelling

G-code Geometric code

ISO International Organization for Standardization

PET-G Polyethylene Terephthalate Glycol

PLA Polylactic acid

RMS Root Mean Square

RP Rapid Prototyping

$S / N \quad$ Signal/Noise

SLA Stereolithography

SLS Selective Laser Sintering

STL Standard Tessellation Language

\section{References}

1. Picard, M., Mohanty, A.K., and Misra, M. "Recent advances in additive manufacturing of engineering thermoplastics: challenges and opportunities", RSC Advances, 10(59), pp. 36058-36089 (2020).

2. Çevik, Ü. and Kam, M. "A review study on mechanical properties of obtained products by FDM method and metal/polymer composite filament production", Journal of Nanomaterials, Special Issue-2020 Micro and Nano Sensors from Additive Manufacturing, 2020(1) pp. 1-9 (2020).
3. Nadagouda, M.N., Ginn, M., and Rastogi, V. "A review of 3D printing techniques for environmental applications", Current Opinion in Chemical Engineering, 28(1), pp. 173-178 (2020).

4. Singh, S., Ramakrishna, S., and Berto, F. "3D Printing of polymer composites: A short review", Material Design \& Processing Communications, 2(2), pp. 97110 (2020).

5. Zhou, L.Y., Fu, J., and He, Y. "A review of 3D Printing technologies for soft polymer materials", Advanced Functional Materials, 30(28), pp. 2000187-2000225 (2020).

6. Vyavahare, S., Teraiya, S., Panghal, D., et al. "Fused deposition modelling: a review", Rapid Prototyping Journal, 26(1), pp. 176-201 (2020).

7. Huang, J., Chen, Q., Jiang, H., et al. "A survey of design methods for material extrusion polymer 3D printing", Virtual and Physical Prototyping, 15(2), pp. 148-162 (2020).

8. Son, T.A., Minh, P.S., and Thanh, T.D. "Effect of $3 \mathrm{D}$ printing parameters on the tensile strength of products", Key Engineering Materials, 863(1) pp. 103-108 (2020).

9. Lalegani Dezaki, M. and Mohd Ariffin, M.K.A. "The effects of combined infill patterns on mechanical properties in FDM process", Polymers, 12(12), pp. 27922812 (2020).

10. Suteja, T.J. and Soesanti, A. "Mechanical properties of $3 \mathrm{D}$ printed polylactic acid product for various infill design parameters: A review", Journal of Physics: Conference Series, 1569 (4), pp. 042010-042017 (2020).

11. Kam, M., Saruhan, H., and İpekçi, A. "Investigation the effect of $3 \mathrm{D}$ printer system vibrations on surface roughness of the printed products", Düzce Üniversitesi Bilim ve Teknoloji Dergisi, 7(2), pp. 147-157 (2019).

12. Kam, M., Saruhan, H., and İpekçi, A. "Investigation the effects of 3D printer system vibrations on mechanical properties of the printed products", Sigma J. Eng and Nat. Sci., 36(3), pp. 655-666 (2018),

13. Kam, M., İpekçi, A., and Saruhan, H. "Investigation of $3 \mathrm{~d}$ printing filling structures effect on mechanical properties and surface roughness of PET-G material products", Gaziosmanpaşa Bilimsel Araştırma Dergisi, 6(Special Issue: ISMSIT2017), pp. 114-121 (2017).

14. İpekçi, A., Kam, M., and Saruhan, H. "Investigation of $3 \mathrm{D}$ printing occupancy rates effect on mechanical properties and surface roughness of PET-G material products", Journal of New Results in Science, 7(2), pp. 1-8 (2018).

15. Kam, M., Saruhan, H., and İpekçi, A. "Farklı doldurma şekillerinin üç boyutlu yazıcılarda üretilen ürünlerin mukavemetine etkisi”, Düzce Üniversitesi Bilim ve Teknoloji Dergisi, 7(3), pp. 951-960 (2019).

16. Sheoran, A.J., and Kumar, H. "Fused deposition modeling process parameters optimization and effect 
on mechanical properties and part quality: Review and reflection on present research", Materials Today: Proceedings, International Conference on Mechanical and Energy Technologies, 21, Greater Noida, India, pp. 1659-1672 (2020).

17. Wibawa, T., Mastrisiswadi, H., and Ismianti, I. "3D print parameter optimization: A literature review", Proceeding of LPPM UPN "Veteran" Yogyakarta Conference Series 2020-Engineering and Science Series, 1, Indonesia, Yogyakarta, pp. 146-151 (2020).

18. Kam, M., İpekçi, A., and ŞengÜl, Ö. "Effect of FDM process parameters on the mechanical properties and production costs of $3 \mathrm{D}$ printed PowerABS samples", International Journal of Analytical, Experimental and Finite Element Analysis, 7(3), pp. 77-90 (2020).

19. Vishwas, M., Basavaraj, C.K., and Vinyas, M. "Experimental investigation using Taguchi method to optimize process parameters of fused deposition modeling for ABS and nylon materials", Materials Today: Proceedings, International Conference on Emerging Trends in Materials and Manufacturing Engineering, 5, Tamil Nadu, India, pp. 7106-7114 (2018).

20. Mahesh, V., Joladarashi, S., and Kulkarni, S.M. "Development and mechanical characterization of novel polymer-based flexible composite and optimization of stacking sequences using VIKOR and PSI techniques", Journal of Thermoplastic Composite Materials, Online First, https://doi.org/10.1177/0892705719864619 (2019).

21. Di Angelo, L., Di Stefano, P., and Guardiani, E. "Search for the optimal build direction in additive manufacturing technologies: A review", Journal of Manufacturing and Materials Processing, 4(3), pp. 7197 (2020).

22. Vishwas, M. and Basavaraj, C.K. "Studies on optimizing process parameters of fused deposition modelling technology for ABS", Materials Today: Proceedings, International Conference on Advanced Materials, Manufacturing, Management and Thermal Science, 4, Tumkur, India, pp. 10994-11003 (2017).

23. Basavaraj, C.K. and Vishwas, M. "Studies on effect of fused deposition modelling process parameters on ultimate tensile strength and dimensional accuracy of nylon", IOP Conference Series: Materials Science and Engineering, International Conference on Advances in Materials and Manufacturing Applications, Bangalore, India, pp. 012035-12047 (2016).

24. Mahesh, V., Joladarashi, S., and Kulkarni, S.M. "Tribo-mechanical characterization and optimization of green flexible composites", Emerging Materials Research, 9(3), pp. 887-896 (2020).

25. Abeykoon, C., Sri-Amphorn, P., and Fernando, A. "Optimization of fused deposition modeling parameters for improved PLA and ABS 3D printed structures", International Journal of Lightweight Materials and Manufacture, 3(3), pp. 284-297 (2020).

26. Carlier, E., Marquette, S., Peerboom, C., et al. "Investigation of the parameters used in fused deposition modeling of poly (lactic acid) to optimize 3D printing sessions", International Journal of Pharmaceutics, 565(2019), pp. 367-377 (2019).

27. Frățilă, D. and Rotaru, H. "Additive manufacturing A sustainable manufacturing route", 4th International Conference on Computing and Solutions in Manufacturing Engineering, 94, Braşov, Romania, pp. 0300403017 (2017).

28. http://www.esun3d.net/products/142.html ESUN Corp., Accessed: 13.05.2021 (2021).

29. Asim, M., Zubair Khan, M., Alam Khan, L., et al. "An integrated approach of quality for polymer composite manufacturing validated and optimized through Taguchi method", Scientia Iranica B, 24(4), pp. 19851995 (2017).

30. Dev, S. and Srivastava, R. "Experimental investigation and optimization of FDM process parameters for material and mechanical strength", Materials Today: Proceedings, 10th International Conference of Materials Processing and Characterization, 26, Mathura, India, pp. 1995-1999 (2020).

31. Nguyen, V.H., Huynh, T.N., Nguyen, T.P., et al. "Single and multi-objective optimization of processing parameters for fused deposition modeling in 3D printing technology", International Journal of Automotive and Mechanical Engineering, 17(1), pp. 7542-7551 (2020).

32. Dey, A. and Yodo, N. "A systematic survey of FDM process parameter optimization and their influence on part characteristics", Journal of Manufacturing and Materials Processing, 3(3), pp. 64-94 (2019).

33. Kam, M., İpekçi, A. and Şengül, Ö. "Investigation of the effect of FDM process parameters on mechanical properties of 3D printed PA12 samples using Taguchi method", Journal of Thermoplastic Composite Materials, (First published online: April 2021) doi:10.1177/08927057211006459 (2021).

\section{Biographies}

Menderes Kam completed his BSc degree at University of Dumlupınar, Kütahya in 2005 and his MSc degree at University of Marmara, İstanbul in 2013. He received his $\mathrm{PhD}$ from the University of Düzce, Düzce. His research interest focuses on the dynamic behavior of shafts, mechanical vibration, metal cutting, additive manufacturing, and optimization.

Ahmet Ípekçi is a Lecturer at the Duzce University. He received his BSc degree in Mechanical Engineering from Sakarya University and MSc degree in Mechanical Engineering from Yildiz Technical University. He studied his $\mathrm{PhD}$ degree in Mechanical Engineering at Marmara University. His research interests include 
reducer, gear systems, machine elements, fatigue, finite elements, vibration, robotic, machine design, additive manufacturing, automated guided vehicles, material science (mechanical properties, retained austenite, residual stress, fatigue life, wear, microstructure, phase analyses, etc.), engineering polymers, heat treatment, and optimization.
Ömer ŞengüL completed his BSc degree at University of Abant Izzet Baysal, Düzce in 2008 and his MSc degree at University of Marmara, İstanbul in 2013. He is currently doing a $\mathrm{PhD}$ in Mechanical Engineering at Düzce University. His research focus is on finite element mitigation, composite materials, and topographic analysis. 